\title{
Large Scale Mobile Medical Service Programme: Data Insights for strengthening local surveillance
}

\author{
Vishal Dogra, Shailendra Hegde, Nitin Rathnam, Sridhar Emmadi, Vishal Phanse \\ Piramal Swasthya, India \\ Objective
}

We report the findings of Andhra Pradesh state's mobile medical service programme and how It is currently used to strengthen the disease surveillance mechanisms at the village level.

Introduction

India has an Integrated Disease Surveillance project that reports key communicable and infectious diseases at the district and subdistrict level. However, recent reviews suggest structural and functional deficiencies resulting in poor data quality [1]. Hence evidence-based actions are often delayed. Piramal Swasthya in collaboration with Government of Andhra Pradesh launched a mobile medical unit (MMU) programme in 2016. This Mobile medical service delivers primary care services to rural population besides reporting and alerting unusual health events to district and state health authorities for timely and appropriate action. The MMU service in the Indian state of Andhra Pradesh is one of the oldest and largest public-private initiatives in India. Two hundred and ninety-two MMUs provide fixed-day services to nearly 20,000 patients a day across 14,000 villages in rural Andhra Pradesh. Every day an MMU equipped with medical (a doctor) and non-medical (1 nurse, 1 registration officer, 1 driver, 1 pharmacist, 1 lab technician, 1 driver) staff visit 2 service points (villages) as per prefixed route map. Each MMU also has its own mobile tablet operated by registration officer for capturing patient details. The core services delivered through MMUs are the diagnosis, treatment, counseling, and free drug distribution to the beneficiaries suffering from common ailments ranging from seasonal diseases to acute communicable and common chronic non-communicable diseases. The routinely collected patient data is daily synchronized on a centrally managed data servers.

\section{Methods}

For this analysis, we used aggregated and pooled data that were routinely collected from August 2016-March 2018. Patient details such as socio-demographic variables (age, sex etc.) medical history and key vitals (random blood sugar, blood pressure, pulse rate etc.) and disease diagnosis variables were analyzed. Besides, communication and action taken reports shared with Government of Andhra Pradesh were also analyzed. We report the findings of the programme with reference to strengthing the village level communicable disease surveillance. Unusual health events were defined as more than 3 patients reporting the epidemiologically linked and similar conditions clustered in the same village.

\section{Results}

We observed 4,352,859 unique beneficiaries registrations and 9,122,349 patient visits. Of all unique beneficiaries, $79.3 \%$ had complete diagnosis details (53\% non-communicable disease, $39 \%$ communicable and $8 \%$ others conditions). A total of 7 unusual health events related to specific and suspected conditions (3 vector-borne diseases related, 4 diarrhea-related) were reported to district health authorities, of which 3 were confirmed outbreaks (1 dengue, 1 malaria, and 1 typhoid) as investigated by local health authorities.

\section{Conclusions}

Mobile medical services are useful to detect unusual health events in areas with limited resources. It increases accountability and response from the Government authorities if the timely information is shared with competent health authorities. Careful evaluation of the mobile health interventions is needed before scaling-up such services in other remote rural areas.

\section{Acknowledgements}

We thank Government of Andhra Pradesh for their support in technical design, implementation and running of this programme. Devesh Varma and Wipro team for the smooth operation of information and technology platform. 
ISDS 2019 Conference Abstracts

\section{References}

1. Kumar A, Goel MK, Jain RB, Khanna P. 2014. Tracking the Implementation to identify gaps in Integrated Disease Surveillance Program in a Block of District Jhajjar (Haryana). J Family Med Prim Care. 3(3), 213-15. PubMed https://doi.org/10.4103/2249-4863.141612

2. Raut D, Bhola A. 2014. Integrated disease surveillance in India: Way forward. Global Journal of Medicine and Public Health. 3(4), 1-10.

Distribution of beneficiaries served as \% of total population in rural Andhra Pradesh, India (2016-2018)

\begin{tabular}{|c|c|c|c|c|c|c|}
\hline District & $\begin{array}{c}\text { Unique } \\
\text { Beneficiaries }\end{array}$ & $\begin{array}{c}\text { Population } \\
\text { (Census 2011) }\end{array}$ & $\begin{array}{c}\% \text { Beneficiaries (Of } \\
\text { total population) }\end{array}$ & $\begin{array}{c}\text { Clinics } \\
\text { conducted } \\
\text { (Total) }\end{array}$ & $\begin{array}{c}\text { Total } \\
\text { Visits }\end{array}$ & $\begin{array}{c}\text { Beneficiaries } \\
\text { per Clinic }\end{array}$ \\
\hline Ananthapur & 418693 & 4081148 & 10 & 25875 & 701840 & 27 \\
\hline Chitoor & 396080 & 4174064 & 9 & 27341 & 862478 & 32 \\
\hline East Godavari & 318134 & 5154296 & 6 & 27201 & 776624 & 29 \\
\hline Guntur & 465287 & 465287 & 10 & 21739 & 833455 & 38 \\
\hline Kadapa & 410485 & 28882469 & 14 & 25363 & 778571 & 31 \\
\hline Krishana & 284671 & 4517398 & 6 & 20508 & 658383 & 32 \\
\hline Nellore & 344783 & 2963557 & 12 & 25263 & 781652 & 31 \\
\hline Prakasam & 374981 & 3397448 & 11 & 21293 & 648130 & 30 \\
\hline Srikakulam & 229690 & 2703114 & 8 & 22174 & 614370 & 28 \\
\hline Vishakhapatnam & 277648 & 4290589 & 6 & 19497 & 557001 & 29 \\
\hline Vizianagram & 219915 & 2344474 & 9 & 17899 & 501483 & 28 \\
\hline West Godavari & 226410 & 3936966 & 6 & 21972 & 698277 & 32 \\
\hline Kurnool & 386082 & 4053463 & 10 & 20808 & 710085 & 34 \\
\hline Total & 4352859 & 49386799 & 9 & 296933 & 9122349 & 31 \\
\hline
\end{tabular}

